\title{
DECISÃO SANCIONATÓRIA DE ÓRGÃO REGULADOR DO EXERCÍCIO DA PROFISSÃO E SUSPENSÃO DOS DIREITOS POLÍTICOS
}

\section{SANCTIONALATORY DECISION OF THE PROFESSION EXERCISE REGULATION AND SUSPENSION OF POLITICAL RIGHTS}

Marcelo José de Souza ${ }^{1}$

\section{RESUMO}

O objetivo da reflexão aqui proposta é informar e esclarecer a implicação da decisão sancionatória de órgão regulador do exercício da profissão no pleno gozo dos direitos políticos. Muitas vezes, o próprio profissional, punido pelo respectivo órgão, desconhece $o$ alcance e as consequências que o ato administrativo punitivo acarretará no exercício de seus direitos políticos em seu cotidiano. Deste modo, a reflexão caminha com a seguinte perspectiva: conceituação de direitos políticos; causa e período de suspensão dos direitos políticos por decisão sancionatória de órgão regulador do exercício da profissão; previsão constitucional e infraconstitucional das inelegibilidades; inelegibilidade e suspensão dos direitos políticos por decisão sancionatória do órgão profissional competente; comunicação à Justiça Eleitoral e lançamento no cadastro eleitoral; quitação eleitoral e inelegibilidade; forma de restabelecimento dos direitos políticos e considerações finais.

PALAVRAS-CHAVE: Direitos políticos; suspensão; órgão regulador; exercício da profissão; inelegibilidades.

\section{ABSTRACT}

The purpose of the reflection proposed here is to inform and clarify the implication of the sanctioning decision of the regulator of the exercise of the profession in the full enjoyment of political rights. Often, the professional himself, punished by the respective body, is unaware of the scope and consequences that the punitive administrative act will entail in the exercise of his political rights in his daily life. Thus, the reflection goes with the following perspective: (1) conceptualization of political rights; (2) cause and period of

\footnotetext{
${ }^{1}$ Especialista em Direito Constitucional pela Universidade do Sul de Santa Catarina (Unisul) Bacharel em Ciências Jurídicas pela Universidade Católica Dom Bosco (UCDB). Pesquisador do Laboratório e Grupo de Estudos em Relações Interétnicas (LAGERI) da Universidade de Brasília (UNB). Aluno Especial do Programa de Mestrado em Direitos Humanos pela Universidade Federal de Mato Grosso do Sul (UFMS). Email - desouzamarcelojose@gmail.com. ORCID - 0000-0001-9341-7689.
} 
suspension of political rights by decision of sanction regulating the exercise of the profession; 2.1 Constitutional and infraconstitutional prediction of ineligibilities; 2.2 Ineligibility and suspension of political rights by decision of the competent professional body; 2.3 Communication to the Electoral Justice and launch in the electoral register; (3) electoral discharge and ineligibility; (4) form of restoration of political rights; and (5) final considerations.

KEYWORDS:Political rights; suspension; regulatory body; exercise of the profession; ineligibility.

\section{CONCEITO DE DIREITOS POLÍTICOS}

A Constituição Federal de 1988 reservou um capítulo exclusivo em seu texto para tratar dos direitos políticos. Esses direitos fazem parte do conjunto dos direitos fundamentais. Não obstante o texto constitucional tratar de aspectos gerais sobre direitos políticos, como seu pleno exercício, cassação, perda e suspensão, não encontramos um conceito expresso na legislação para um entendimento sobre a sua natureza e abrangência.

Para tanto, a doutrina do eminente Pedro Lenza conceitua os direitos políticos do seguinte modo:

[...] os direitos políticos nada mais são do que instrumentos por meio dos quais a Constituição Federal (CF) garante o exercício da soberania popular, atribuindo poderes aos cidadãos para interferirem na condução da coisa pública, seja direta, seja indiretamente (LENZA, 2009, p. 785).

Sendo assim, os cidadãos interferirão na condução do destino de seu país na medida em que possam exercer com mais ou menos intensidade o gozo de seus direitos políticos. A perda ou suspensão dos direitos políticos determinará a restrição no grau de participação do cidadão na vida pública de seu país, sem contar as implicações que possam afetar o âmbito de sua vida privada.

Quanto aos direitos fundamentais, Alexandre de Moraes traz a seguinte definição:

O conjunto institucionalizado de direitos e garantias do ser humano que tem por finalidade básica o respeito de sua dignidade, por meio de sua proteção contra o arbítrio do poder estatal e o estabelecimento de 
condições mínimas de vida e desenvolvimento da personalidade humana (MORAES, 2002, p. 20).

Deste modo, a perda ou a suspensão dos direitos políticos acarretará restrições para que o ser humano tenha condições de desenvolver de forma digna e plena sua personalidade enquanto pessoa e também junto ao corpo social.

O Direito Eleitoral é um dos ramos do direito público que trata, dentre outras, das questões inerentes aos direitos políticos. Os direitos políticos, assim como os direitos civis, fazem parte da denominada primeira geração ou dimensão dos direitos humanos, ou ainda direitos de liberdade. A forma como os direitos políticos serão disciplinados é um ato de soberania do Estado, tratando-se de assuntos internos a serem sistematizados por cada país.

Não obstante, os direitos políticos são instrumento para a manutenção da existência do próprio regime democrático, sendo alcançados pela proteção internacional dos direitos humanos. A Corte Interamericana de Direitos Humanos (Corte IDH), assim definiu os direitos políticos:

Os direitos políticos, entendidos como aqueles que reconhecem e protegem o direito e o dever de todos os cidadãos de participar na vida política de seu pais, para a Corte, são por essência direitos que propiciam o fortalecimento da democracia e do pluralismo político (CORTE IDH, 2009, tradução nossa).

Em outras palavras, os direitos políticos correspondem a titularidades que, consideradas em conjunto, são a mais ampla expressão da participação política.

Os direitos políticos transcendem o âmbito interno do direito constitucional e nos dias atuais são reconhecidos como uma das categorias dos direitos humanos. A Declaração Universal dos Direitos Humanos (DUDH), adotada em 10 de dezembro de 1948, dispõem em seu artigo 21:

1. Todo ser humano tem o direito de tomar parte no governo de seu país diretamente ou por intermédio de representantes livremente escolhidos.

2. Todo ser humano tem igual direito de acesso ao serviço público do seu país.

3. A vontade do povo será a base da autoridade do governo; esta vontade será expressa em eleições periódicas e legítimas, por sufrágio 
universal, por voto secreto ou processo equivalente que assegure a liberdade de voto.

(ONU, 1948).

Ainda podemos observar os direitos políticos em outros diplomas internacionais como a Convenção Americana sobre Direitos Humanos (CADH) e o Pacto Internacional dos Direitos Civis e Políticos (PIDCP). A democracia é um valor de destaque no âmbito do direito internacional e no próprio Sistema Interamericano é objeto de exame atos que violem esse direito. Assim, os direitos políticos são importante instrumento para a existência do próprio Estado e um recurso para impedir o surgimento de regimes tiranos.

\section{CAUSA E PERÍODO DE SUSPENSÃO DOS DIREITOS POLÍTICOS POR DECISÃO SANCIONATÓRIA DE ÓRGÃO REGULADOR DO EXERCÍCIO DA PROFISSÃO}

As inelegibilidades podem ser classificadas como absolutas e relativas. As absolutas estão previstas de maneira expressa no texto constitucional e estão relacionadas às características pessoais (estrangeiros, conscritos, analfabetos). A Constituição Federal ainda estabelece algumas hipóteses de inelegibilidades relativas (em razão do cargo ou parentesco) e autoriza, por lei complementar, a criação de outras com fins específicos dispostos pelo legislador constituinte.

A decisão sancionatória de órgão regulador do exercício da profissão, trata-se de causa de inelegibilidade absoluta que enseja o impedimento para qualquer cargo político-eletivo, independentemente de a eleição ser presidencial, federal, estadual ou municipal. Sua ocorrência possibilita a arguição de inelegibilidade, por intermédio de Ação de Impugnação de Registro de Candidatura (AIRC), podendo culminar na negação ou no cancelamento do registro, e na anulação do diploma, caso já expedido (GOMES, 2013).

A decisão de exclusão do exercício profissional compete a cada conselho profissional, nos termos do respectivo estatuto, desde que a decisão administrativa não seja anulada ou suspensa pelo Poder Judiciário. Neste caso específico, não é suficiente apenas a propositura da ação judicial, faz-se necessária decisão de cunho 
judicial (definitiva ou provisória) que anule ou suspenda a sanção do órgão regulador do exercício da profissão.

A doutrina caminha nesse sentido, conforme podemos observar:

É mister, para nós, para se cogitar da incidência desta alínea, tenha operado o trânsito em julgado da decisão administrativa que, no órgão de classe, Ihe impôs a sanção disciplinar de exclusão do exercício da profissão. Decisões provisórias, em caso de tamanha gravidade, são imprestáveis para o sancionamento político de inelegibilidade. Ficaria carente de correção jurídica nos depararmos com um profissional ainda exercendo sua profissão, apesar de ter sido expulso de seu órgão de classe, mas impedido de, por esta mesma razão, candidatar-se a um mandato eletivo. (CÂNDIDO, 2012, p. 151).

Importante ainda consignar que o órgão regulador da profissão deverá proporcionar um processo justo, para que seja livre de nulidades, atentando-se aos direitos e garantias fundamentais que também são assegurados na esfera administrativa. O devido processo legal é garantia constitucional presente e de observância obrigatória em todas as instâncias estatais (legislativa, jurisdicional e administrativa).

Deste modo, abordaremos a fundamentação jurídica para a aplicação da suspensão dos direitos políticos pelo órgão regulador do exercício profissional, sua duração, comunicação à Justiça Eleitoral e a respectiva anotação no cadastro nacional de eleitores.

\section{PREVISÃO CONSTITUCIONAL E INFRACONSTITUCIONAL DAS INELEGIBILIDADES}

A Constituição Federal de 1988 introduziu em seu texto de forma expressa as hipóteses gerais de inelegibilidades no art. 14, $\S \S 4^{\circ}$ a $7^{\circ 02}$. No entanto, fora as hipóteses

$2 \quad \S 4^{\circ}$ São inelegíveis os inalistáveis e os analfabetos.

§ 5ㅇ O Presidente da República, os Governadores de Estado e do Distrito Federal, os Prefeitos e quem os houver sucedido, ou substituído no curso dos mandatos poderão ser reeleitos para um único período subseqüente. 
taxativas supramencionadas no $\S 9^{\circ}$ do mesmo artigo, autorizou a edição de lei complementar para estabelecer outros casos de inelegibilidades e os prazos de sua cessação com o fim específico de proteger a probidade administrativa, a moralidade para exercício de mandato considerada a vida pregressa do candidato, e a normalidade e legitimidade das eleições contra a influência do poder econômico ou o abuso do exercício de função, cargo ou emprego na administração pública.

Para atender ao disposto no texto constitucional, o legislador editou a Lei Complementar n. 64, de 18 de maio de 1990, onde estabeleceu de acordo com o art. 14, § 9o da Constituição Federal, casos de inelegibilidades, prazos de cessação e determinou outras providências.

A Lei Complementar n. 64/90 trazia dois pontos importantes. Em primeiro, estabelecia que o candidato só ficaria inelegível depois de uma condenação definitiva, ou seja, com o trânsito em julgado da sentença condenatória. Em segundo, que a inelegibilidade seria aplicada por três anos após o cumprimento da pena.

Ocorre que, quase vinte anos depois, foi editada a Lei Complementar n. 135, de 4 de junho de 2010, que alterou a Lei Complementar n. 64/90, estabelecendo novos casos de inelegibilidades para ampliar a proteção da probidade administrativa e da moralidade no exercício do mandato.

Em uma breve retrospectiva, a Lei da Ficha Limpa surgiu de um projeto de lei de iniciativa popular, com campanha organizada pelo MCCE (Movimento de Combate à Corrupção Eleitoral), com início em abril de 2008. Em setembro de 2009, o projeto de lei foi protocolado na Câmara dos Deputados com em torno de 1.600 .000 assinaturas. Em maio de 2010 a Câmara concluiu a votação e oito dias após o texto foi aprovado pelo Senado Federal. Ainda em junho do mesmo ano, o Presidente da República sancionou a nova lei.

$\S 6$ o Para concorrerem a outros cargos, o Presidente da República, os Governadores de Estado e do Distrito Federal e os Prefeitos devem renunciar aos respectivos mandatos até seis meses antes do pleito.

$\S 7^{0}$ São inelegíveis, no território de jurisdição do titular, o cônjuge e os parentes consangüíneos ou afins, até o segundo grau ou por adoção, do Presidente da República, de Governador de Estado ou Território, do Distrito Federal, de Prefeito ou de quem os haja substituído dentro dos seis meses anteriores ao pleito, salvo se já titular de mandato eletivo e candidato à reeleição. 
A constitucionalidade da Lei da Lei da Ficha Limpa foi judicializada com início no Tribunal Superior Eleitoral (TSE). O cerne da questão era saber se a lei poderia ser aplicada nas eleições do ano de sua aprovação, tendo em vista o princípio da anualidade eleitoral disposto no art. 16 da Constituição Federal. O TSE entendeu que a lei poderia ser aplicada já nas eleições de 2010.

Em fevereiro de 2012, após concluir a análise de ações conjuntas de controle concentrado de constitucionalidade, como observaremos posteriormente, o Supremo Tribunal Federal (STF), por maioria de votos, declarou a constitucionalidade da referida lei e a possibilidade de ser aplicada já no pleito eleitoral de 2012, alcançando, inclusive, fatos pretéritos ocorridos antes de sua vigência.

Deste modo, no presente momento, as inelegibilidades estão previstas de forma expressa na Constituição e nas Leis Complementares 64/90 e 135/10.

\section{INELEGIBILIDADE E SUSPENSÃO DOS DIREITOS POLÍTICOS POR DECISÃO SANCIONATÓRIA DO ÓRGÃO PROFISSIONAL COMPETENTE}

No que pertine ao presente estudo, trata-se aqui, especificamente, do disposto no art. 1ㅜ, inciso I, alínea m, da Lei Complementar nํ64/90, acrescentado pela Lei Complementar ํo 135/10, o qual dispõe:

m) os que forem excluídos do exercício da profissão, por decisão sancionatória do órgão profissional competente, em decorrência de infração ético-profissional, pelo prazo de 8 (oito) anos, salvo se o ato houver sido anulado ou suspenso pelo Poder Judiciário, (BRASIL, 2010).

Como se pode observar, a norma objetiva incidir a inelegibilidade aos que forem excluídos do exercício da profissão por decisão do órgão profissional competente, em razão de infração ético-profissional, pois, se infringiu os padrões mínimos éticos exigidos por sua classe profissional, não reserva a moralidade para o exercício do mandato exigida pelo art. 14, § 9º, da CF (PANUTTO, 2013).

Todas as profissões que tiverem seu exercício regulado em lei, submeterão seus profissionais ao registro e fiscalização por esses órgãos específicos doravante denominados conselhos de fiscalização profissional, ou também conhecidas como 
conselhos de classe, que possuem a natureza jurídica de autarquia e personalidade jurídica de direito público. Confira-se a seguinte ementa de julgado do STF:

ADMINISTRATIVO. RECURSO EXTRAORDINÁRIO. CONSELHO DE FISCALIZAÇÃO PROFISSIONAL. EXIGÊNCIA DE CONCURSO PÚBLICO. ART. 37, II, DA CF. NATUREZA JURÍDICA. AUTARQUIA. FISCALIZAÇÃO. ATIVIDADE TÍPICA DE ESTADO. 1. Os conselhos de fiscalização profissional, posto autarquias criadas por lei e ostentando personalidade jurídica de direito público, exercendo atividade tipicamente pública, qual seja, a fiscalização do exercício profissional, submetem-se às regras encartadas no artigo 37, inciso II, da CF/88, quando da contratação de servidores. 2. Os conselhos de fiscalização profissional têm natureza jurídica de autarquias, consoante decidido no MS n. 22.643, ocasião na qual restou consignado que: (i) estas entidades são criadas por lei, tendo personalidade jurídica de direito público com autonomia administrativa e financeira; (ii) exercem a atividade de fiscalização de exercício profissional que, como decorre do disposto nos artigos 5ำ XIII, 21, XXIV, é atividade tipicamente pública; (iii) têm o dever de prestar contas ao Tribunal de Contas da União. 3. A fiscalização das profissões, por se tratar de uma atividade típica de Estado, que abrange o poder de polícia, de tributar e de punir, não pode ser delegada (ADI 1.717), excetuando-se a Ordem dos Advogados do Brasil (BRASIL, 2012)

Em relação ao dispositivo supra, foi proposta junto ao STF, a Ação Direta de Inconstitucionalidade (ADIN) n 4.578, proposta pela Confederação Nacional dos Profissionais Liberais (CNPL), analisada de forma conjunta com outras ações via controle concentrado de constitucionalidade.

A CNPL, em termos gerais, sustentou que o dispositivo era inconstitucional por conceder às decisões administrativas dos conselhos de classe um status de decisão judicial de órgão colegiado, ferindo o princípio da razoabilidade. Ainda, trouxe à baila que os conselhos exercem a fiscalização das atividades profissionais de seus membros, de modo que as sanções administrativas deveriam ter efeitos apenas no âmbito da respectiva corporação.

Por fim, concluindo julgamento, o STF reconheceu a constitucionalidade da Lei Complementar no 135/10, declarando constitucionais as hipóteses de inelegibilidades ora instituídas, nos termos do voto do Ministro Luiz Fux, cuja orientação foi no sentido de que houve proporcionalidade na regulamentação da lei, estando presentes os 
pressupostos da adequação, necessidade e proporcionalidade em sentido estrito, nos seguintes termos:

[...] o sacrifício exigido à liberdade individual de candidatar-se a cargo público eletivo não supera os benefícios socialmente desejados em termos de moralidade e probidade para o exercício de cargos públicos, sobretudo porque ainda são rigorosos os requisitos para que se reconheça a inelegibilidade. (BRASIL, 2012a, p. 35).

Quanto ao conceito de inelegibilidade, o então Ministro Fernando Neves, do Tribunal Superior Eleitoral, assim a definiu "A inelegibilidade importa no impedimento temporário da capacidade eleitoral passiva do cidadão, que consiste na restrição de ser votado, não atingindo, portanto, os demais direitos políticos, como, por exemplo, votar e participar de partidos políticos" (BRASIL, 2004, p. 1).

A inelegibilidade ataca a capacidade eleitoral passiva do cidadão, constituindo num impedimento do exercício passivo da cidadania, ou seja, não serão atingidos todos seus direitos políticos. Neste caso em particular, ele não poderá colocar seu nome para passar pelo crivo popular para postular a um cargo eletivo, sendo impedido de ser votado. Assim, a inelegibilidade poderá constituir-se num impedimento absoluto ou relativo de poder candidatar-se a um mandato político no Poder Legislativo ou Executivo.

As inelegibilidades, conforme previsão constitucional, tem por fim proteger a normalidade e legitimidade das eleições contra a influência do poder econômico ou abuso do exercício da função, cargo ou emprego na administração direta ou indireta, nos termos do art. 14, $\$ 9^{\circ}$ da Constituição Federal.

Deste modo, as inelegibilidades trazem uma carga ética muito forte, não obstante, não pode estabelecer um fundamento ético injusto e desproporcional com os princípios fundamentais da base do próprio Estado Democrático.

A inelegibilidade decorrente de infração ético-profissional acarreta uma condição impeditiva ao exercício pleno da cidadania. O cidadão será detentor de direitos políticos ativos, porém, seus direitos políticos passivos estarão suspensos pelo prazo previsto em lei. Estamos diante de uma inelegibilidade relativa, onde o cidadão, na ocasião do pleito eleitoral, ficará impedido de pleitear um cargo ou função eletiva. A lei 
complementar é o único instrumento autorizado pela Constituição para a criação e estabelecimento de prazos das inelegibilidades relativas, pois, as absolutas, estão previstas de forma taxativa no próprio texto constitucional.

\section{COMUNICAÇÃO À JUSTIÇA ELEITORAL E LANÇAMENTO NO CADASTRO ELEITORAL}

A Justiça Eleitoral é responsável pela administração, manutenção e preservação da integridade do cadastro nacional de eleitores. As informações constantes do cadastro serão tratadas, de forma exclusiva, pela Justiça Eleitoral. Toda a inserção e exclusão de dados será realizada por determinação da autoridade judiciária eleitoral competente. Recebida a comunicação de fato que possa ensejar suspensão de direitos políticos, assim como sua regularização, caberá à autoridade judiciária a apreciação, decisão e adoção das medidas cabíveis, na esfera administrativa, com a imediata atualização do cadastro eleitoral.

A Lei oㅜ 4.737, de 15 de julho de 1965, Código Eleitoral, dispõe em seu art. 71, $\S 2^{\circ}:$

Art. 71. São causas de cancelamento:

$\S 2^{\circ}$ No caso de ser algum cidadão maior de 18 (dezoito) anos privado temporária ou definitivamente dos direitos políticos, a autoridade que impuser essa pena providenciará para que o fato seja comunicado ao juiz eleitoral ou ao Tribunal Regional da circunscrição em que residir o réu. (BRASIL, 1965)

Deste modo, no caso de decisão sancionatória de órgão regulador do exercício profissional, em decorrência de infração disciplinar, fato este ensejador de inelegibilidade, caberá ao respectivo conselho o encaminhamento dessa informação à Justiça Eleitoral.

Questão importante a pontuar é quanto à competência para decidir sobre a suspensão ou anulação de decisão imposta pelo órgão regulador do exercício da profissão quando impõe a exclusão do profissional dos seus quadros. No caso, a 
competência será da Justiça Comum nos termos do que foi decidido pelo TSE no Recurso Especial Eleitoral N³44-30:

[...] Eventuais vícios procedimentais que contaminem a decisão que culminou na exclusão do candidato do exercício da profissão não são passíveis de análise pela Justiça Eleitoral no processo de registro de candidatura, sem prejuízo de eles serem alegados em sede própria para que, a partir da obtenção de provimento judicial do órgão competente, a inelegibilidade prevista na alínea $\mathrm{m}$ do inciso I do art. $1^{\circ}$ da Lei Complementar $\mathrm{n}^{\circ} 64 / 90$ possa ser afastada. Recurso especial não provido. (BRASIL, 2013, p. 1).

Por longos anos, as comunicações de suspensão e/ou restabelecimento de direitos políticos, conscrição e óbitos, pelos órgãos competentes da Justiça Eleitoral, era feita de forma física, via ofício. Atualmente, essa informação dá-se por meio de recurso eletrônico de comunicação, a exemplo do Sistema de Informações de Direitos Políticos - INFODIP, utilizado pela Justiça Eleitoral do Estado do Mato Grosso do Sul.

Nos termos do Provimento no 16/2012 da Corregedoria Regional Eleitoral do Mato Grosso do Sul, procura-se estabelecer o procedimento desde a comunicação do conselho profissional à efetiva suspensão dos direitos políticos passivos do cidadão pela Justiça Eleitoral. A Lei Complementar no 64/90, com as alterações introduzidas pela Lei Complementar no 135/10, na hipótese específica do art. 1ํㅡㄹ inciso I, alínea m, ensejará a anotação no cadastro eleitoral, do código de Atualização da Situação do Eleitor - ASE 540 (inelegibilidade).

A contar do recebimento da comunicação pelo sistema INFODIP, a anotação no cadastro nacional de eleitores deverá ocorrer no prazo de quinze dias. Com a devida anotação no cadastro, o eleitor ficará inelegível pelo prazo de oito anos, período de suspensão dos direitos políticos passivos, com todas as demais implicações decorrentes da lei, a não ser que o ato que ensejou a suspensão, no caso, a penalidade imposta pelo conselho profissional, houver sido anulado ou suspenso pelo Poder Judiciário. 


\section{QUITAÇÃO ELEITORAL E INELEGIBILIDADE}

A quitação eleitoral faz prova da regularidade do eleitor com a Justiça Eleitoral. O TSE no Processo Administrativo № 313-98, passou a entender que as anotações constantes do cadastro eleitoral que ensejam inelegibilidade, não mais importam em restrição ao conceito de quitação eleitoral, servindo apenas como subsídio para que a autoridade judiciária competente, no momento do pedido do registro de candidatura, decida pelo seu deferimento ou não, in verbis:

[...] a inelegibilidade não deve ser considerada causa restritiva à quitação eleitoral, servindo o RMS no 1026-79.2015.6.26.0000/SP eventual registro da circunstância apenas como subsídio para o exame do pedido do registro de candidatura, a título de 'ocorrência de inelegibilidade'.

[...] A inelegibilidade, tida como causa de restrição à capacidade eleitoral passiva, não pode impor, em ofensa aos princípios do contraditório e da ampla defesa, limitações à quitação eleitoral de forma automática, devendo as ocorrências porventura consignadas no cadastro eleitoral a esse título servir como elemento embasador do exame, pela autoridade judiciária competente, de eventual pedido de registro de candidatura a cargo eletivo.

Assim, proponho ao Pleno desta Corte que:

a) a inelegibilidade não mais seja considerada causa restritiva à quitação eleitoral, servindo o eventual registro de tal informação no cadastro eleitoral apenas como subsídio para a autoridade judiciária eleitoral competente no momento do exame de pedido de registro de candidatura, a título de "ocorrência de inelegibilidade"; (BRASIL, 2015, p 1,11 e 17)

No julgamento supramencionado, ainda afirmou a Corte Eleitoral que o impedimento à quitação eleitoral daqueles que tenham somente registro de inelegibilidade em seu histórico no cadastro de eleitores consiste em indevida extrapolação dos efeitos da condenação criminal, ultrapassada a extinção da pena. A inelegibilidade atinge somente um dos núcleos da capacidade eleitoral do cidadão, no caso - o passivo (jus honorum), tendo em vista sua função constitucional precípua de proteger a probidade administrativa e a moralidade para o exercício de cargos eletivos.

Nos termos da Resolução TSE no 21.823/2004, podemos destacar: 
O conceito de quitação eleitoral reúne a plenitude do gozo dos direitos políticos, o regular exercício do voto, salvo quando facultativo, o atendimento a convocações da Justiça Eleitoral para auxiliar os trabalhos relativos ao pleito, a inexistência de multas aplicadas, em caráter definitivo, pela Justiça Eleitoral e não remitidas, excetuadas as anistias legais, e a regular prestação de contas de campanha eleitoral, quando se tratar de candidatos. (BRASIL, 2004, p. 1).

Conforme ora explicitado, a contrário sensu, o eleitor inelegível poderá exercer o direito do voto nos pleitos eleitorais e, ainda, não ficará impedido de adquirir passaporte ou carteira de identidade; fazer parte de concorrência pública ou administrativa em qualquer instituição; pedir empréstimos; receber salário de entidades públicas ou assistidas pelo governo; reivindicar documentos que necessitem da quitação eleitoral; renovar matrícula em qualquer instituição de ensino pública ou fiscalizada pelo governo e se inscrever em concursos públicos ou tomar posse em cargos públicos.

Não obstante, no âmbito do Poder Judiciário, o Conselho Nacional de Justiça (CNJ, 2012), responsável pelo controle da atuação administrativa deste poder em nível nacional, proibiu a designação para função de confiança ou a nomeação para cargo em comissão de pessoa que tenha praticado os atos que especifica, tipificados como causa de inelegibilidade prevista na legislação eleitoral.

Nestes termos, os excluídos do exercício da profissão, por decisão sancionatória judicial ou administrativa do órgão profissional competente, não poderão exercer função de confiança ou cargo em comissão no Poder Judiciário, a não ser após o decurso do prazo de cinco anos da decisão que tenha ocasionado a exclusão do exercício da profissão, nos termos do parágrafo único, inciso II, do art. $3^{\circ}$ da Resolução CNJ $156 / 2012$.

\section{FORMA DE RESTABELECIMENTO DOS DIREITOS POLÍTICOS}

Compete ao eleitor com inscrição suspensa por decisão sancionatória do órgão profissional comprovar a cessação dos motivos ensejadores da causa de suspensão dos seus direitos políticos. Nos casos de inelegibilidades, comprovam sua cessação certidão ou outro documento hábil apresentado pelo eleitor, tudo, nos termos do Provimento n 16/12 da Corregedoria Regional Eleitoral do Mato Grosso do Sul. 
A Justiça Eleitoral não realiza de ofício o levantamento da suspensão dos direitos políticos, a não ser quando provocada pelo órgão competente ou pelo próprio interessado. Veja a decisão do TSE no Processo Administrativo № 936-31:

PROCESSO ADMINISTRATIVO. CONSULTA. ART. 15, III, DA CONSTITUIÇÃO FEDERAL. CONDENAÇÃO CRIMINAL. EXTINÇÃO DA PUNIBILIDADE. MULTA NÃO SATISFEITA. SUSPENSÃO. DIREITOS POLÍTICOS. PERMANÊNCIA. INELEGIBILIDADE. ART. I, e, DA LC N 64/90. ANOTAÇÃO. A pendência de pagamento da pena de multa, ou sua cominação isolada nas sentenças criminais transitadas em julgado, tem o condão de manter/ensejar a suspensão dos direitos políticos prevista pelo art. 15, III, da Constituição Federal. O registro inserido na Base de Perda e Suspensão de Direitos Políticos somente será desativado quando cessados os motivos da suspensão, o que deverá ser comprovado pelo interessado ou comunicado pelo órgão competente. Nos termos do art. I, e, da LC $n^{\circ} 64 / 90$, o prazo de inelegibilidade, hipótese que abrange somente os condenados pelos crimes previstos no mencionado dispositivo, projeta-se por oito anos após o cumprimento da pena imposta, seja ela privativa de liberdade, restritiva de direito ou multa. Necessidade de reiteração às corregedorias regionais eleitorais da orientação adotada por esta Corte Superior em relação ao tema (BRASIL, 2019, p. 1).

Assim como no recebimento da comunicação de suspensão dos direitos políticos, caberá à autoridade judiciária a apreciação, decisão e adoção das medidas cabíveis, na esfera administrativa, visando o restabelecimento dos direitos políticos por meio da anotação, no cadastro eleitoral, do código de Atualização da Situação do Eleitor - ASE 558 (restabelecimento de inelegibilidade).

Os pedidos de restabelecimento de direitos políticos de eleitor serão decididos, em regra, pelo juiz da zona eleitoral da inscrição do eleitor. No caso de pessoas sem inscrição ou cancelada pelo ASE 450 (sentença de autoridade judiciária), a decisão caberá ao Corregedor Regional Eleitoral.

No caso de eleitor pertencente à zona eleitoral de outra unidade da federação, o cartório eleitoral deverá encaminhar à respectiva Corregedoria Regional Eleitoral, por meio do INFODIP, a comunicação de suspensão ou restabelecimento, conscrição, óbitos ou inelegibilidade para as providências pela autoridade judiciária competente. 


\section{CONSIDERAÇÕES FINAIS}

Refletiu-se aqui, de forma objetiva, sobre o alcance das decisões sancionatórias do órgão regulador da profissão que vai além da esfera administrativa do respectivo conselho de fiscalização profissional, implicando na suspensão dos direitos políticos passivos do eleitor. Essa suspensão interfere no exercício pleno da cidadania, impedindo o eleitor de participar de forma ativa na vida política e nos rumos de seu país, podendo atuar apenas como coadjuvante dentro regime democrático.

A decisão sancionatória pelo órgão competente traz uma dura pena, incidindo o condenado em uma causa de inelegibilidade por um prazo de oito anos. Portanto, além da perda do registro junto ao órgão competente para o exercício da profissão, ficará inabilitado para o exercício de cargo eletivo nos Poderes Executivo e Legislativo, enquanto durar a respectiva sanção.

A inelegibilidade como decorrência da decisão sancionatória do órgão regulador da profissão acarreta uma punição de caráter temporário, durante o lapso temporal previsto em lei, fazendo com que num pleito eleitoral para escolha de mandatários, o cidadão possa exercer apenas parcialmente seus direitos políticos, no caso específico, votar e não ser votado.

Não obstante, conforme já apontado neste trabalho, é entendimento pacífico no âmbito do Tribunal Superior Eleitoral que quitação eleitoral é condição de elegibilidade e a inelegibilidade afeta apenas a capacidade eleitoral passiva do cidadão, visando proteger a probidade administrativa e a moralidade para o exercício do cargo público a ser postulado.

A ocorrência de inelegibilidade anotada no cadastro eleitoral será um elemento importante para que a autoridade judiciária eleitoral possa fazer a devida apreciação, no momento do registro de candidatura, e decidir se o requerente pode ou não colocar o seu nome a disposição do eleitorado na disputa de um cargo eletivo. Caso o diploma já tenha sido expedido, poderá haver sua cassação por inelegibilidade superveniente ao registro de candidatura.

A causa de inelegibilidade prevista no art. 1o, inciso I, alínea $\mathrm{m}$, da Lei Complementar nำ64/90, acrescentado pela Lei Complementar ํㅜ 135/10, visa proteger 
a probidade administrativa e a moralidade no exercício do mandato, mas, ao mesmo tempo, dá às decisões dos conselhos de fiscalização profissional, efeitos que vão além do seu âmbito administrativo, interferindo de forma direta na vida política do cidadão.

\section{REFERÊNCIAS}

BRASIL. Constituição Federal de 1988. Brasília: Senado Federal, 1988. Promulgada em 5 de outubro de 1988. Disponível em <http://www.planalto.gov.br/ccivil_03/constituicao/constituição.htm>. Acesso em 08 ago. 2019.

. Lei no 4.737. Institui o Código Eleitoral. In: Diário Oficial da República

Federativa do Brasil, Brasília, DF, 19 de julho de 1965. Disponível em

<http://www.planalto.gov.br/ccivil_03/leis/l4737.htm>. Acesso em 23 dez. 2019.

Superior Tribunal Eleitoral. REspe 344-30 Recurso rejeitado sobre pedido de reconsideração de candidatura negada em função da perda do registro profissional. , Rel. Min. Henrique Neves da Silva. Ministério Público Eleitoral e Paulo Roberto de Jesus Luna. 19 de fevereiro de 2013. Disponível em $<$ http://inter03.tse.jus.br/InteiroTeor/pesquisa/actionGetBinary.do?tribunal=TSE\&proces soNumero=34430\&processoClasse $=$ RESPE\&decisaoData=20130219 >. Acesso em 23 dez. 2019.

. Supremo Tribunal Federal. Ação Direta de Inconstitucionalidade 3.026. Ação movida pela PGR que analisou vínculo empregatício da Ordem dos Advogados do Brasil.Procuradoria Geral da República, Presidente da República e Congresso Nacional

Rel. Min. Eros Grau. 8 de junho de 2006. Disponível em $<$ http://redir.stf.jus.br/paginadorpub/paginador.jsp?docTP=AC\&doclD=363283>. Acesso em 23 dez. 2019.

. Superior Tribunal Eleitoral. Agravo Regimental no Agravo de Instrumento 4598. Ação que confirmou cassação de mandato eletivo em razão da rejeição de contas. Sebastião de Sena Rosa Neto, Delsuita Carvalho Correia Bona e Raimundo Nonato Bona Carboreto. Rel. Min. Fernando Neves. 03 de junho de 2004. Disponível em $<$ http://temasselecionados.tse.jus.br/temas-selecionados/inelegibilidades-e-condicoesde-elegibilidade/parte-ii-temas-diversos-sobre-inelegibilidades-e-condicoes-deelegibilidade/conceito-de-inelegibilidade/generalidades >. Acesso em 23 dez. 2019.

Supremo Tribunal federal. Ação Direta de Inconstitucionalidade no 4578. Ação que analisou, em conjunto, constitucionalidade e inconstitucionalidade da Lei Complementar 135/14 e $§ 9^{\circ}$ do art. 14 da Constituição Federal. Confederação Nacional das Profissões Liberais.Ministro Relator Luiz Fux.16 de fevereiro de 2012. Disponível 
em: <http://redir.stf.jus.br/paginadorpub/paginador.jsp?docTP=TP\&doclD=2257978> . Acesso em: 08 ago. 2019.

. Tribunal Regional Eleitoral de Mato Grosso do Sul. Provimento no 04/2015CRE/MS: Dispõe sobre o Sistema de Informações de Direitos Políticos - INFODIP, para a tramitação das comunicações de suspensão e/ou restabelecimento de direitos políticos, conscrição e óbitos, por meio eletrônico, nesta Corregedoria Regional Eleitoral e zonas eleitorais desta circunscrição. 17 de setembro de 2015. Disponível em: <http://www.tre-ms.jus.br/legislacao/provimentos/provimentos-do-trems $>$. Acesso em: 08 ago. 2019.

. Tribunal Regional Eleitoral de Mato Grosso do Sul. Provimento no 16/12 $\overline{\mathrm{CRE}} / \mathrm{MS}$ : Aprova o Manual de Práticas Cartorárias dos Cartórios Eleitorais desta circunscrição. Manual de ASE - Instruções para a utilização dos códigos de Atualização da Situação do Eleitor (ASE). 3 de dezembro de 2012. Disponível em: $<$ http://www.tre-ms.jus.br/legislacao/provimentos/provimentos-do-tre-ms $>$. Acesso em: 08 ago. 2019.

Conselho Nacional de Justiça. Resolução 15. Proíbe a designação para função de confiança ou a nomeação para cargo em comissão de pessoa que tenha praticado os atos que especifica, tipificados como causa de inelegibilidade prevista na legislação eleitoral, e dá outras providências. 8 de agosto de 2012. Disponível em: <https://www.cni.jus.br/wpcontent/uploads/2013/04/resol gp 156 2012.pdf>. Acesso em: 08 ago. 2019.

. Tribunal Superior Eleitoral. Processo Administrativo 936-31MS. Processo administrativo. Consulta. Art. 15, iii, da Constituição Federal. Condenação criminal. Extinção da punibilidade. Multa não satisfeita. Suspensão. Direitos políticos. Permanência. Inelegibilidade. Art. 1, 1, e, da Ic n 64/90. Anotação. Interessado: TRE/MS. Relator: Ministra Laurita Vaz. 23 de abril de 2015. Disponível em: http://inter03.tse.jus.br/InteiroTeor/pesquisa/actionGetBinary.do?tribunal=TSE\&processo Numero=93631\&processoClasse $=P A \&$ decisaoData $=20150423$. Acesso em: 23 dez . 2019.

. Tribunal Superior Eleitoral. Processo Administrativo oㅜ 313-98.2013.6.00.000. Elegibilidades atingidas pela Lei Complementar 135/2010. Interessado: Corregedoria Regional Eleitoral de MS. 2015. Disponível em: < https://tse.jusbrasil.com.br/jurisprudencia/239237088/processo-administrativo-pa-31398ms/inteiro-teor-239237099 >. Acesso em: 08 ago. 2019.

. Tribunal Superior Eleitoral. Recurso Especial Eleitoral 344-30 BA. Eleições 2012. Registro de candidatura. Recurso Especial. Alínea $m$ do inciso 1 do art. $1^{\circ}$ da Lei Complementar $n^{\circ}$ 64190. Incidência. Relator: Ministro Henrique Neves da Silva. Paulo Roberto de Jesus Luna e Ministério Público Eleitoral. 19 de fevereiro 2013. Disponível em: Disponível em: http://inter03.tse.jus.br/InteiroTeor/pesquisa/actionGetBinary.do?tribunal=TSE\&processo 
Numero $=34430$ \&processoClasse $=$ RESPE\&decisaoData $=20130219$. Acesso em: 22 dez. 2019.

. Tribunal Superior Eleitoral. Recurso extraordinário 539.224/CE. Relator: Ministro Luiz Fux., 18 de junho de 2012. Disponível em: $<$ http://redir.stf.jus.br/paginadorpub/paginador.jsp?docTP=TP\&doclD=2187962>. Acesso em: 22 dez. 2019.

. Tribunal Superior Eleitoral. Res.-TSE no 21.538/2003: Dispõe sobre o alistamento e serviços eleitorais mediante processamento eletrônico de dados, a regularização de situação de eleitor, a administração e a manutenção do cadastro eleitoral, o sistema de alistamento eleitoral, a revisão do eleitorado e a fiscalização dos partidos políticos, entre outros. 2003. Disponível em: <www.tse.jus.br>. Acesso em: 08 ago. 2019.

. Tribunal Superior Eleitoral. Res.-TSE no 21.823/2004: Dispõe sobre Quitação eleitoral. Abrangência. Pleno gozo dos direitos políticos. Exercício do voto. Atendimento à convocação para trabalhos eleitorais. Inexistência de multas pendentes. Prestação de contas de campanha. Registro de sanções pecuniárias de natureza administrativas previstas no Código Eleitoral e na Lei no 9.504/97. Pagamento de multas em qualquer juízo eleitoral. Aplicação analógica do art. 11 do Código Eleitoral. 2004. Disponível em: <www.tse.jus.br>. Acesso em: 08 ago. 2019.

CÂNDIDO, Joel J. Direito eleitoral brasileiro. 15. ed. rev. atual. e ampl. São Paulo: Edipro, 2012.

GOMES, José Jairo. Direito eleitoral. 9. ed. São Paulo: Atlas, 2013

LENZA, Pedro. Curso de direito constitucional esquematizado. 13. ed. rev. Atual. e ampl. São Paulo: Saraiva, 2009.

MORAES, Alexandre de. Direitos humanos fundamentais: Teoria Geral. 4ª̣ed. São Paulo: Atlas, 2002.

ONU. Declaração Universal dos Direitos Humanos. 1988. Disponível em: $<$ https://www.unidosparaosdireitoshumanos.com.pt/course/lesson/articles-19-25/readarticle-21.html >. Acesso em 23 dez. 2019.

PANUTTO, Peter. Inelegibilidades: um estudo dos direitos políticos diante da Lei da Ficha Limpa. São Paulo: Verbatim, 2013.

PICADO, Sonia. Derechos políticos como derechos humanos. In NOHLEN, Dieter; et al. (comps.). Tratado de Derecho Electoral Comparado de América Latina. México: FCE, 2007. 